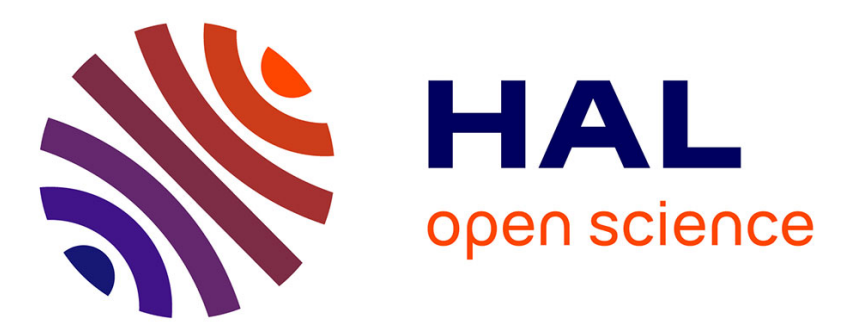

\title{
Novel Mechanical Design of Biped Robot SHERPA Using 2 DOF Cable Differential Modular Joints
}

\author{
Ionut Mihai Constantin Olaru, Sébastien Krut, François Pierrot
}

\section{To cite this version:}

Ionut Mihai Constantin Olaru, Sébastien Krut, François Pierrot. Novel Mechanical Design of Biped Robot SHERPA Using 2 DOF Cable Differential Modular Joints. IROS: Intelligent Robots and Systems, Oct 2009, St. Louis, MO, United States. pp.4463-4468, 10.1109/IROS.2009.5354425 . lirmm00429945

\section{HAL Id: lirmm-00429945 \\ https://hal-lirmm.ccsd.cnrs.fr/lirmm-00429945}

Submitted on 13 Nov 2009

HAL is a multi-disciplinary open access archive for the deposit and dissemination of scientific research documents, whether they are published or not. The documents may come from teaching and research institutions in France or abroad, or from public or private research centers.
L'archive ouverte pluridisciplinaire HAL, est destinée au dépôt et à la diffusion de documents scientifiques de niveau recherche, publiés ou non, émanant des établissements d'enseignement et de recherche français ou étrangers, des laboratoires publics ou privés. 


\title{
Novel Mechanical Design of Biped Robot SHERPA Using 2 DOF Cable Differential Modular Joints
}

\author{
Ionut Mihai Constantin Olaru, Sébastien Krut, François Pierrot
}

\begin{abstract}
This paper discusses the mechanical kinematics solutions and design aspects of the biped robot SHERPA, a bipedal platform able to walk and carry load. Starting from the analysis of the human lower limbs, we figure out that 6 DOF per leg are fundamental for a correct walking motion and can be adopted in a mechanical design of a humanoid robot. A close investigation of the joints leads us to a novel modular mechanical design, with a parallel architecture mechanism characterized by and high degree of interchangeable components. The robot is using twelve high performance hollow shaft electrical actuators acting in pairs in a parallel manner, a remote compact and transparent actuation with zero-backlash cable transmissions, 2 DOF differential joints between each segment of the limb and a light-weight carbon fiber skeleton modeling and mimic the anatomy of the human legs. The modular 2 DOF cable differential joint has been implemented at the hip, knee and ankle level. Using our approach, actuation is more transparent (back-drivable, with low inertia) and will allow SHERPA to interact with the environment more smoothly which leads to better walking ability.
\end{abstract}

\section{INTRODUCTION}

$\mathrm{T}$ HE ability of legged robots to pass over obstacles, to walk on uneven terrain, to climb stairs, to walk in corridors or to move inside of a human designed environment is a better design solution than using wheeled robots. As a result, starting from early 1970's when Kato [1] introduced one of the first static biped robot, numerous projects where created [2], [3], [4], [5] and efforts around the whole world have been made to create a machine able to walk on a flat on uneven terrain, to climb stairs, to change direction during walking or to walk up and down slopes.

Despite the long history of approaching humanoid and biped walking research, even in present, the realization of a humanoid robot able to overcome all this challenges is still far from being reached partly because of hardware limitation, in terms of mechanical design, partly because of control complexity. The achievements of a qualitative machine able to mimic the human gait relies in a tight cooperation between researches from different areas such as mechanical design, automatic control, computer architectures and all other technological issues involved in such a complex project.

Concerning only the mechanical aspect, most humanoid robots developed so far have been built using industrial-robot-like technology (classical electric actuators,

The authors are with LIRMM, CNRS and Université Montpellier 2, 161 rue Ada, 34092 Montpellier, France.

(e-mail:ionut.olaru@hotmail.com,krut@lirmm.fr, pierrot@lirmm.fr). reduction gears, joints arranged in a serial manner). As a result, the power-to-weight ratio has not been optimized. Biped walking machines using different types and sources of energy such as, pneumatic, hydraulic or electrical energy have been tested by different research teams around the world using external or onboard power supply [6]-[11].

Even if the combination "classical motors + gears + serial arrangement" fits industrial requirements (high precision and rigidity) it may not be the best to address humanoid robots requirements.

A new technology is proposed here (based on high-torque actuators, cable transmission with no backlash, and parallel configuration) to fulfill the humanoid robots needs in a better way. Hence using our technology, actuation is more transparent (backdrivable, with low inertia) and may allow our prototype to interact with the environment more smoothly thus leading to higher quality walking. Furthermore, thanks to modular design, the overall structure remains quite simple. Called SHERPA after the name of Sherpa population in Nepal, our robot is a biped walking machine and should be able to carry loads. It is based on a parallel actuation and tendon driving elements. Our aim was to create a model able to reproduce the human gait during walking, and to design a more efficient structure with a high power-to-mass. For this reason, the main structure of the robot was chosen with anthropomorphic characteristic, having the segment lengths and range of movement for the joints similar with the one in the human lower limbs. Using a modular concept for the cable differential joints, combined with parallel mechanism concept, a zero backlash cable differential transmission as well as a new hollow shaft actuator, we intend to obtain a new architecture of a biped walking machine unifying these innovative concepts and overcoming some of the drawbacks existing in the design of existing robots. In the following sections of this paper, we concentrate on detailed aspects over the mechanical design as well as the principle used to design different mechanical subassemblies and parts of SHERPA.

\section{Kinematic StRUCTURE OF SHERPA}

As stated before, despite of the anthropomorphic characteristics of our robot, we did not try to copy completely the human model with all degrees of freedom but we considered the minimum number of DOF involved to obtain a smooth walking and to be adaptable to complete different tasks depending on the environmental constrains, like normal walking on horizontal terrain and slopes, obstacles, and direction change during walking. 
A close look on the anatomy of human legs (Fig. 1.), inspired us to go further and chose a cable driven elements having in mind the tendon driven / bone segments of human beings. The skeletal-muscle architecture of the lower limb of

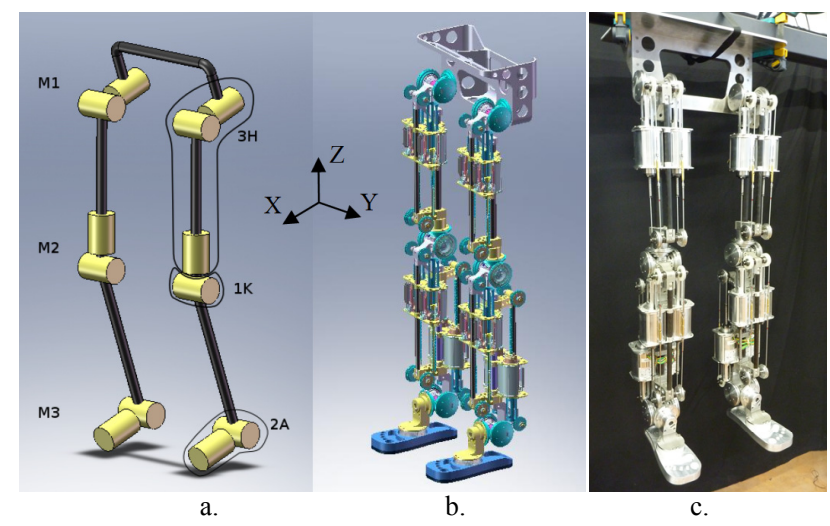

Fig. 2 a. Robot Kinematics, b. CAD model of SHERPA

the human body is often considered as having 9 DOF for walking. In the same time a high redundancy in DOF might become a drawback, creating problems for control. Zatsiorsky [12] exemplifies the role of each joint in human body and the consequences of some DOF neglected during walking and the maximum amplitude of the movements.

Since SHERPA robot design focuses only on legs, Fig.1 helps analyzing the kinematics of human body and modeling the lower limbs; we found suitable that a total of 6 DOF per leg will be sufficient to reproduce human gait for walking. A configuration $3 \mathrm{H} / 1 \mathrm{~K} / 2 \mathrm{~A}$, as in Fig. 1.a. (3DOF-Hip / 1DOF-Knee / 2DOF-Ankle), is sufficient to meet the requirement for our purpose: walking on flat terrain, walking up and down slopes, and changing direction during walking.

However, thanks to the modular mechanical design implementation, the distribution of DOF in the case of our robot is: $2 \mathrm{DOF}$ for hip articulation, 2 DOF for knee and 2 DOF for ankle level.

A better understanding of the physical placement of the joints and of the principle the way they act on the real structure of the robot is depicted in Fig 2, where on the left side (2.a) is presented the DOF distribution in the way they are physically placed on the robot, on the middle side (2.b.) is given the explanation on how the $2^{\text {nd }}$ degree of freedom from the knee level is transferred on the hip, while on the right image (2.c) is presented the mechanical structure - prototype of SHERPA Robot.

Table I. synthesizes the maximum amplitude and the range of movement of human articulations. Since the modular design of the joints implies the use of the same module for each joint, we considered the maximum amplitude of the main flexion as equal to $140^{\circ}$ and that the secondary rotation amplitude in the joint as equal to $60^{\circ}$.

Achieving this extended range of motion the mechanical design of the module and the customization of each joint allow us to setup a $-5^{\circ}$ bend back for the knee joint. This feature will allow SHERPA robot at least form the mechanical point of view and later when a control strategy will be investigated in the future works, to perform walking with a strait leg as humans do and not as actual robots with a flexed knee.

TABLE I

RANGE OF MOVEMENT FOR A LEG IN A HUMAN BODY

\begin{tabular}{lccc}
\hline & \multicolumn{3}{c}{ Maximal Amplitude } \\
& Hip & Knee & Ankle \\
\hline Flexion & $130^{\circ}$ & $140^{\circ}$ & - \\
Extension & $15^{\circ}$ & $-5^{\circ}$ & - \\
Plantar Flexion & - & - & $30-60^{\circ}$ \\
Dorsal Flexion & - & - & $30^{\circ}$ \\
Adduction & $30^{\circ}$ & - & $-15^{\circ}$ \\
Abduction & $45^{\circ}$ & - & $+15^{\circ}$ \\
Rotation & Ext. $=60^{\circ}$ & Ext. $=30^{\circ}$ & - \\
\hline \hline
\end{tabular}

Aspect of the maximum range of movement of SHERPA will be discussed in section V. paragraph B. "Tension, Stroke computation and Ball bearing Screw Dimensioning" where more details will be given from the point of view of the engineering design decision.

The kinematics and the dynamics of walking is a widely studied subject in biomechanics. In 1951, Bresler and Frankel [13] identified the values of the articulation torques for a human subject of $55 \mathrm{~kg}$. During the 80 's Winter published additional values regarding the subject mass (N.m/Kg) [14]. In 1995 Kuster [15] evaluated the torques during down slope walking and in 2006 McIntosh [16] presented his results for up and down slope walking.

Table II gives torque measurements for a male subject, presents the maximal values of the torques and the amplitude of anatomic joint recorded in the literature for up and down walking on a slope. Those values are computed considering inertia moments and the mass segments of a male subject (trunk without arms).

One important aspect when designing human-inspired robot architecture is the estimation of mechanical parameters of the leg segments. Investigating the values relative to segment lengths indicated by Clauser [17], de Leva [18] [19], Zatsirosky [20], Stein [21], we concluded to choose the leg segments defined as the distance between the axes of rotation, considering also the mechanical constrains of the modular design. For the tibia segment, from the axis of the ankle up to the knee axis the segment length is $475 \mathrm{~mm}$, while the length for the femoral segment between the knee axis and the hip is $503 \mathrm{~mm}$. The overall height of the robot measured on the CAD model, between the ground (plane of the foot), up to the upper plane on the pelvis is $1285 \mathrm{~mm}$.

\section{CABle DifFEREnTIAL JoInT CONCEPT}

Most robots, manipulators or humanoids, rely on gears transmission. On the opposite Barrett [22] proposed to use cable transmission systems which bring a number of advantages such as: high power/mass ratio for the mechanical transmission, compliance, remote and easy placement of actuators. For our design we use two small special designed identical motors to drive the load instead of using a single 


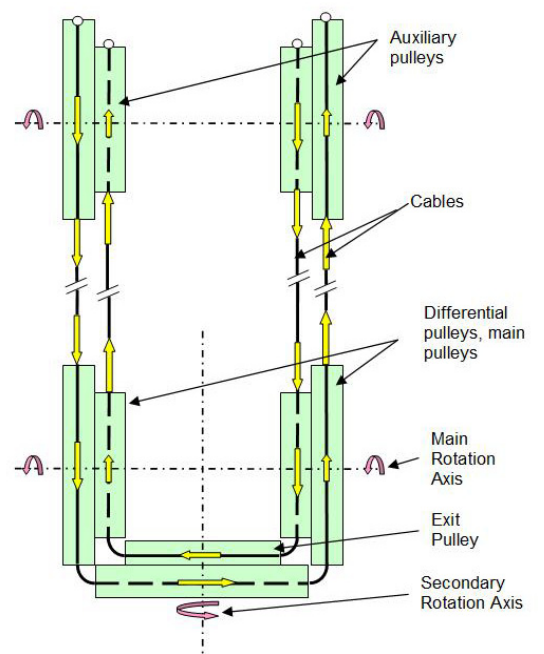

Fig. 3 Cable differential principle and kinematics scheme

over dimensioned and powerful actuator, thanks to a differential system.

Traditional differentials use gears in order to transmit the power, but here the proposed design is based on high-torque actuators, cable transmission with no backlash using cable differential joint. The cable differential uses cables in order to transfer the power from the input to the output.

In case of our joint we can define two axes of rotation. The first rotation will occur when the both motors are acting in the same direction, both cables will be pulled in the same direction, and as a result the joint will perform the rotation around the main axis of rotation. When the motors are acting in opposite directions the main pulleys will rotate in opposite directions and this will perform the rotation around the secondary rotation axis. The cable differential principle and its kinematics scheme are represented in Fig. 3. while the CAD model of the whole assembly and the prototype are presented in Fig. 7.

TABLE II

TORQue MEASUREMENTS For A MALE SUBJect

\begin{tabular}{|c|c|c|c|c|c|}
\hline & \multirow{2}{*}{$\begin{array}{c}\text { JOINT } \\
\text { Flexion }\end{array}$} & \multicolumn{2}{|c|}{ Normal Walking } & \multicolumn{2}{|c|}{ Up and down Walking } \\
\hline & & $\begin{array}{l}70 \mathrm{Nm} \\
0.85 \mathrm{Nm} / \mathrm{kg}\end{array}$ & $30^{\circ}$ & $1.5 \mathrm{Nm} / \mathrm{kg}$ & $60^{\circ}$ \\
\hline \multirow{4}{*}{$\begin{array}{l}\mathrm{H} \\
\mathrm{I} \\
\mathrm{P}\end{array}$} & Extension & $\begin{array}{l}0.35 \mathrm{Nm} \\
0.6 \mathrm{Nm} / \mathrm{kg}\end{array}$ & $20^{\circ}$ & $1.5 \mathrm{Nm} / \mathrm{kg}$ & $15^{\circ}$ \\
\hline & Adduction & $85 \mathrm{Nm}$ & - & $0.8 \mathrm{Nm} / \mathrm{kg}$ & - \\
\hline & Abduction & $25 \mathrm{Nm}$ & - & $0.2 \mathrm{Nm} / \mathrm{kg}$ & - \\
\hline & Rotation & $\begin{array}{l}\text { Int. / Ext.: } \\
17 \mathrm{Nm}\end{array}$ & - & - & - \\
\hline K & Flexion & $\begin{array}{l}66 \mathrm{Nm} \\
0.4 \mathrm{Nm} / \mathrm{kg}\end{array}$ & $50^{\circ}$ & $2.5 \mathrm{Nm} / \mathrm{kg}$ & $85^{\circ}$ \\
\hline $\begin{array}{l}\mathrm{N} \\
\mathrm{E} \\
\mathrm{F}\end{array}$ & Extension & $\begin{array}{l}45 \mathrm{Nm} \\
0.25 \mathrm{Nm} / \mathrm{kg}\end{array}$ & $0^{\circ}$ & $0.75 \mathrm{Nm} / \mathrm{kg}$ & $0^{\circ}$ \\
\hline & Rotation & $\begin{array}{l}\text { Int. / Ext.: } \\
17 \mathrm{Nm}\end{array}$ & - & - & - \\
\hline $\begin{array}{l}\mathrm{A} \\
\mathrm{N}\end{array}$ & Plantar Flexion & $\begin{array}{l}110 \mathrm{Nm} \\
1.5 \mathrm{Nm} / \mathrm{kg}\end{array}$ & $25^{\circ}$ & $1.6 \mathrm{Nm} / \mathrm{kg}$ & $20^{\circ}$ \\
\hline $\begin{array}{l}\mathrm{K} \\
\mathrm{L}\end{array}$ & Dorsal Flexion & $\begin{array}{l}30 \mathrm{Nm} \\
0 \mathrm{Nm} / \mathrm{kg}\end{array}$ & $10^{\circ}$ & $-0.5 \mathrm{Nm} / \mathrm{kg}$ & $20^{\circ}$ \\
\hline $\mathrm{E}$ & Rotation - Tilt & $\begin{array}{l}\text { Int. / Ext.: } \\
17 \mathrm{Nm}\end{array}$ & - & - & - \\
\hline
\end{tabular}
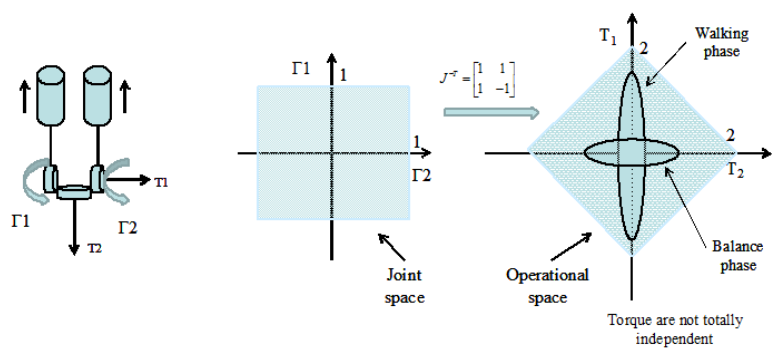

Fig. 4. Velocities and Torques in Joint space respectively in the operational space

\section{The Benefit of PARAllel ACTUATION ON A DIFFERENTIAL JOINT}

Nowadays, humanoid robots are designed using a classical serial configuration of the actuators to achieve multiple DOF in joints. However, the torque requirements about each axis of the multi-dof joints are not equal: for the hip, the movement in the sagital plane (during walking phase) requires a higher torque value than the movement in the frontal plane (during balance phase). Classical design leads to selecting either (i) two identical high-torque motors (and thus, one will be under loaded) or (ii) two different motors (which is not convenient for modular design).

Our design uses two identical motors which "combine" their actuation torques to create operational torques around both axis of the joint. For a better understanding of the parallel actuation technology, Fig. 4. synthesizes in a diagram form the torques representation in joint space and in the operational space.

During the walking phase, as well as during the balance phase, we can observe that using the parallel actuation and 2 DOF differential joint, the torques in the operational space (about both axes of the joint) are not independent. The maximum torque for balance phase is constrained by the torque in the walking phase.

Indeed the relation between the joint torque vector $\gamma$ and the operational torque vector $\boldsymbol{\tau}$ is given by:

$$
\tau=\mathbf{J}^{-\mathbf{T}} \gamma
$$

With: $J=\left[\begin{array}{cc}1 / 2 & 1 / 2 \\ 1 / 2 & -1 / 2\end{array}\right]$

Then, the value of the output operational torque will be twice the torque of one actuator. This aspect has a major impact on the overall weight, size and compactness of the mechanical structure and as a result the power/weight ratio will be increased optimizing the overall design of the mechanical structure of the robot.

\section{Mechanical TRANSMisSion}

Considering the well known drawbacks of the classical transmission using gears and gearboxes we decided in our design to implement elements to overcome lack of performance which may occur using those technologies. Knowing that the ball screws are perfectly suited for robotic 
applications due to their high efficiency (efficiency $\geq 90 \%$ ) no backlash, no starting torque, back drivability and silent operation, we decide to use a similar transmission in order to transform the rotational movement of the actuator in a linear movement. The transmission consists in a hollow shaft electrical motor, a ball screw transforming the rotation of the hollow shaft electrical actuator in a translation movement. This is transforming the hollow shaft rotational actuator in a linear actuator suitable for our application. Connected to a cable the pulling force will be transferred into the cable differential system and redirected to the output pulleys to produce the active rotations.

\section{A. Transmission Ratio Computation}

Relation (2) is used to express the relation between the input and output of our system and to compute the transmission ratio. $\omega_{a}$, represents the angular displacement of the actuator and $\omega_{j}$ the angular displacement of the pulley, $R$ is the pulley radius (in our case $40 \mathrm{~mm}$ ), and the screw pitch $L$, a constant defined by the screw manufacturer, in our case $L=1 \mathrm{~cm}$. For any revolution of the actuator rotor there is an output displacement of $1 \mathrm{~cm}$ of the ball bearing screw. The obtained transmission ratio is 1:25.

$$
\begin{aligned}
& \frac{\varpi_{j}}{\varpi_{a}}=\frac{L}{2 \pi R} \cong 0.0397 \cong \frac{1}{25} \\
& \omega_{\mathrm{j}} / \omega_{\mathrm{a}}=1: 25
\end{aligned}
$$

Having a transmission ratio $\omega_{j} / \omega_{a}=1: 25$, among with a small inertia device, combined with the advantage of using a ball bearing screw with an efficiency of $>90 \%$, leads to a transparent device (back-drivable and with low inertia).

\section{B. Tension, Stroke Computation and Ball Bearing Screw Dimensioning}

The parallel actuation of the cable differential joint requires the basic calculation of the total stroke in order to dimension the active length of the ball bearing screw. To maintain the modular design of the architecture of the robot we calculate the equivalent stroke as being the stroke corresponding to the maximum value of the angle of the overall range of movement in the human body for Hip, Knee and Ankle.

In Fig. 5. is presented the general computation scheme for combined stroke between the 2 DOF's of the same joint corresponding to an angle $\theta_{I}=140^{\circ}$ representing the active angle (range of motion) for the main rotation and an angle $\theta_{2}=60^{\circ}$ active angle (range of motion) for the secondary rotation.

According with the stroke computation scheme, and considering identical radius $R$ for the pulleys, the total stroke $S$ can be computed as the sum of the arc length corresponding to each angle and is given by relation (4).

$$
S=R \cdot \theta_{1}+R \cdot \theta_{2}
$$

where: $S$ is the total stroke $S=S_{1}+S_{2}$, defined as the sum between $S_{I}$ (the length of circular sector for the main rotation) and $S_{2}$ (the length of circular sector for the 2 nd rotation). Total length of the ball bearing screw can be computed as a sum between the total active stroke $S$, the nut length and the estimated clearance.

\section{Cable Tension Computation}

To compute cable tension we use the kinematics' relation (5), where the screw displacement $d$ is expressed as a function of the screw pitch $L$ and $\theta$ the angular displacement of the rotor

$$
d=\frac{L}{2 \pi} \theta
$$

Considering that $\eta$ represents the efficiency of the ball screw (in our case 90\%), and knowing the necessary torque in the joint from the anthropomorphic data, the required force in the cable is calculated as follows (to achieve the torque necessary in normal walking):

$$
\tau=\frac{F \cdot L}{2 \cdot \pi \eta}
$$

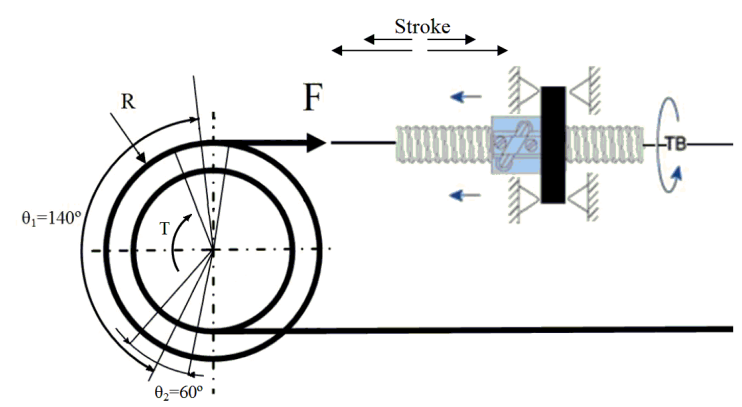

Fig. 5. Force / Stroke schematic diagram.

\section{DESIGN INVESTIGATIONS AND PROTOTYPE}

Several mechanical designs implementation were investigated: (i) differential mechanism using straight profile pulleys, (ii) differential mechanism using profiled " $U$ " shape pulleys, (iii) parallel mechanism using rods and spherical joints, (iiii) parallel mechanism using contact spherical joints. Based on functionality, simplicity, robustness, weight characteristics and the degree of the modularity, we considered for the final design the differential joint using cables and straight profile pulleys. Isolating the subassembly of the cable differential joint, a more detailed presentation of the CAD model can be observed in fig. 6 .

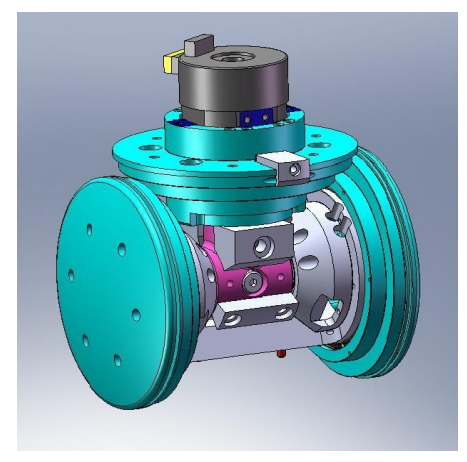

Fig. 6. CAD model of the cable differential joint 


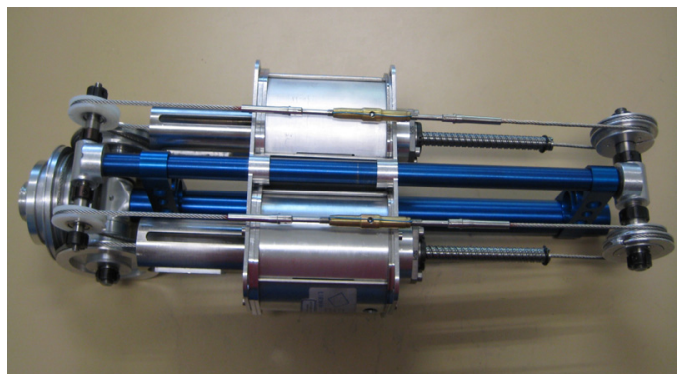

(a.) Module 2 DOF first prototype

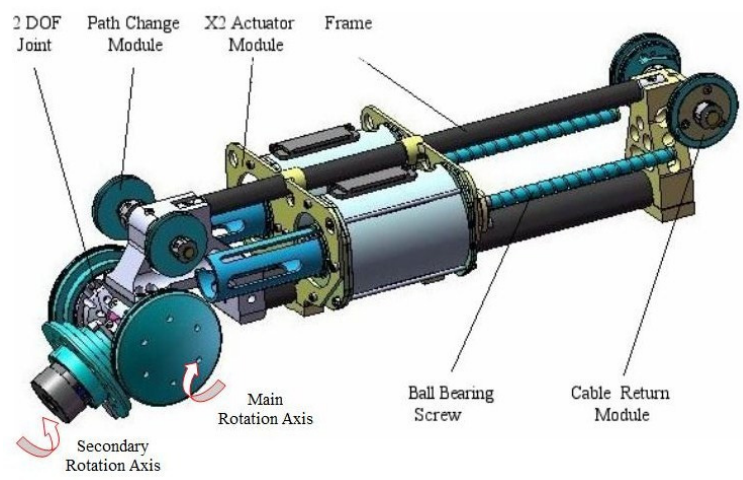

(b.) CAD model final assembly

Fig. 7. Design of modular 2DOF cable differential

The final configuration of the joint allows us to tune different setups regarding the destination location of the joint. Joint configuration within the range of movement corresponding with hip, knee or ankle angle values, is achieved by interchangeable mechanical stops that can be assembled in corresponding configurations.

To eliminate the geometrical misalignment on the cable path, the cable return pulley module, and the winding pulleys were designed to be axial adjustable. A tensioning devices using Left - Right threads for cable ends were installed to assure the cable pretension. With no encoders and with dummy actuators, a first prototype of the module assembly of 2 DOF cable differential joint has been build (Fig. 7. (a)). The CAD model final assembly Fig. 7.b of 2 DOF cable differential joint shows the main rotation axis, as well as the secondary rotation axis, achieved by the joint module the CAD representation includes also the absolute encoders embedded in the joint structure.

\section{ACTUATION}

In order to meet the design specifications and the project requirements avoiding the multiple drawbacks of the market actuators we decided to design a special purpose light weight hollow shaft electrical actuator.

Considering the complexity of the traditional engineering design solutions, (see Garrec [23], [24]) using conventional brushless actuators and rotational to linear transmission modules, as well the use of reduction gear boxes to transform the rotation of the actuator to a translation motion, we have decided to minimize the number of components, to reduce the total weight of the transmission and to obtain a transparent back drivable and low inertia transmission.

Our design in Fig. 8 integrates in the body of the actuator the actuator itself and the rotational-to-linear movement

TABLE III.

PARAMETER COMPARISON CHART

SHERPA ACTUATOR VS. COMMERCIAL ETEL MOTOR

\begin{tabular}{ccc}
\hline \hline ERNEO Motor & Characteristics & ETEL Motor \\
\hline SHERPA002V1 & Reference & TMA 070-030 \\
\hline $250 \mathrm{rpm}$ & Nominal speed & $250 \mathrm{rpm}$ \\
$1.65 \mathrm{Nm}$ & Nominal torque & $0.86 \mathrm{~N} . \mathrm{m}$ \\
$20^{\circ} \mathrm{C}$ & Nominal heating $\left(\right.$ at $\left.40^{\circ} \mathrm{C}\right)$ & $20^{\circ} \mathrm{C}$ \\
$15 \mathrm{~W}$ & Nominal power dissipation & $22 \mathrm{~W}$ \\
0.74 & Nominal efficiency & 0.5 \\
$3 \mathrm{~N} . \mathrm{m}$ & Pulse torque $\Delta \mathrm{t}=60 \mathrm{~s}$ & $3 \mathrm{~N} \cdot \mathrm{m}$ \\
$47 \mathrm{~W}$ & Pulse power dissipation & $315 \mathrm{~W}$ \\
$60^{\circ} \mathrm{C}$ & Pulse heating & $>250^{\circ} \mathrm{C}$ \\
0.63 & Pulse efficiency & 0.2 \\
$72 \mathrm{~mm}$ & Stator exterior diameter & $70 \mathrm{~mm}$ \\
$54 \mathrm{~mm}$ & Rotor inner diameter & $35 \mathrm{~mm}$ \\
$39 \mathrm{~mm}$ & Active length & $30 \mathrm{~mm}$ \\
$69 \mathrm{~mm}$ & Total length & $60 \mathrm{~mm}$ \\
$0.46 \mathrm{~kg}$ & Active mass & $0.55 \mathrm{~kg}$ \\
$3.58 \mathrm{Nm} / \mathrm{kg}$ & (iron-copper-magnet) & $1.56 \mathrm{~N} . \mathrm{m} / \mathrm{kg}$ \\
\hline
\end{tabular}

transformation module in just one element.

The hollow shaft rotor and all actuator machined parts are made from aluminum alloy. The active $\mathrm{Si}-\mathrm{Fe}$ magnetic plates cover the exterior diameter of the rotor while the permanent magnets are placed on the external diameter of the Si-Fe plates in order to increase the magnetic properties of the rotor. Using this technology the resulted rotor is very light comparing with conventional ones. Connecting directly the ball screw nut with the stator, the rotational movement is transferred to the screw. To avoid the rotation of the screw an anti-rotation device was implemented in the actuator design and attached to the stator.

Two identical actuators are assembled in parallel to build the X2 module and to power the 2DOF's joint which is used in the modular architecture of the robot. The light weight design of the actuator and the new technology involved using a light weight rotor as a permanent magnet and a thin section stator, lead to a high performance actuator in terms of mass-to-torque ratio as well as limited volume.

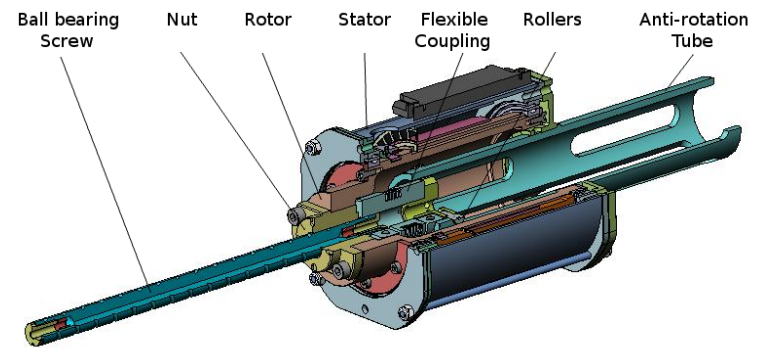

Fig. 8. Cut out section view of the hollow shaft actuator and ball bearing transmission

The hollow shaft rotative actuator associated with high pitch ball bearing screw leads to high force backdrivable linear actuator. In Table III, are stated the physical parameters of our hollow shaft actuator designed specially for this 
application, and use to build the humanoid robot Sherpa in contrast with the commercial available ETEL industrial actuator, shown here as an example of an excellent existing motor. Despite of its small dimensions, the exterior diameter is $\varnothing 77 \mathrm{~mm}$ and the overall length is $212 \mathrm{~mm}$ including the nut and anti-rotation device, the actuator is able to produce a nominal torque of $1.65 \mathrm{Nm}$ having a total weight of the body including the anti-rotation module device of $1.3 \mathrm{~kg}$.

\section{SEnsorial System EMbedded on Mechanical STUCTURE}

The control of the robot requires information about the posture of the robot as well as the reaction forces and moments occurring at the foot level. For this reason some of the basic sensors used for postural control of the robot have been implemented in the structure, being embedded in the mechanical design. Two ATI - Mini85 with compact low profile design, high capacity with large measurement range, and six axis Force/Torque sensors have been embedded at the foot level. A total of 12 absolute encoders HENGSTLER AD36 optical sensing technology have been implemented in the structure of the robot. Each joint embeds in its design two absolute encoders, one for each axis of rotation. The design placement of each encoder gives the absolute position of the angles between the leg segments sending positional feedback to control the robot.

Each actuator is designed with three Hall effect sensors per actuator for the coils control feedback. Information received from those sensors is used to commutate the electrical phases of the actuator.

\section{COnClusions And Future Work}

In order to identify the mechanical failure of the machined components and the lifting capacity of the actuator we setup a testing bench loading the system with weights up to $120 \mathrm{~kg}$, which is way over the expected load. All mechanical parts were performing normal and none of them show any sign of mechanical failure. The heating diagram shows that during functionality the temperature of the actuator was $40^{\circ} \mathrm{C}$. The successful test run, for identifying the mechanical failure of the mechanical components of the actuator, demonstrate also the lifting capacity of the actuator and its characteristic to produce necessary torque to drive the cable differential joint.

The conceptual and mechanical design of SHERPA biped robot was presented in this paper with focus on kinematics principles and mechanical solutions and implementations. Within our design we succeed to develop a bipedal machine with expected advanced walking capabilities able to carry loads. As we submit this paper for publication, the final prototype version of Sherpa robot is in assembly phase in our laboratory.

\section{ACKNOWLEDGEMENTS}

This research was supported by the French National Research Agency, ANR-06-BLAN-0244-01. Authors received support from colleagues of Institut d'Electronique du Sud, Montpellier, France.

\section{REFERENCES}

[1] I. Kato, H. Tsuik, "The Hydraulically powered Biped Walking Machine With a High Carrying Capacity". Proc. $4^{\text {th }}$ Int. Sys. on External Control of Human Extremities, 1972.

[2] M. Vukobratovic, Legged Locomotion Robots: "Mathematical Models, Control Algorithms and Realizations”, Belgrade: M. Pupin, 1975.

[3] K. Hirai, M. Hirose, Y. Haikawa, T. Takenaka, "The Development of Honda Humanoid Robot" Proc. of ICRA, pp 1321-1326, 1998.

[4] M. Okada, T. Shinohara, T. Gotoh, S. Ban, Y. Nakamura: "Double Spherical Joint and Backlash Clutch for Lower Limbs of Humanoids" Proc. of 2003 IEEE ICRA, Taipei, Taiwan, sept 14-19, 2003.

[5] K. Kaneko, S. Kajita, F. Kanehiro, K. Yokoi, K. Fujiwara, H. Hirukawa, T. Kawasaki, M. Hirata, T. Isozumi: "Design of Advanced Leg module for Humanoid Robotics Project of METI", Proc. of Int. Conference on Robotics \& Automation, pp. 38-45, 2002.

[6] B. Espiau, P. Sardain, "The anthropomorphic biped robot BIP2000" Proceedings of ICRA IEEE International Conference on Robotics and Automation, vol. 4, pp. 3996 - 4001, 2000.

[7] J. W. Hurst, J. E. Chestnutt, A. Rizzi "Design and Philosophy of the BiMASC, a Highly Dynamic Biped" Proc of 2007 IEEE Int. Conference in Robotics and Automation, Roma Italy 10-14 April 2007.

[8] S. Lohmeier, T. Buschmann, H. Ulbrich, F. Pfeiffer "Modular Joint Design for Performance Enhanced Humanoid Robot LOLA" Proc. of ICRA, Orlando Florida May 2006.

[9] F.B. Ouezdou, R. Sellaouti, A. Konno, B. Mohamed, V. Scesa, P. Henaff "Design and experiments of a torso mechanism for the ROBIAN biped robot” Robotica Vol. 24, Issue 3, May 2006.

[10] G. Gini, U. Scarfogliero, M. Folgheraiter "Human-Oriented Biped Robot Design: Insights into the Development of a truly Anthropomorphic Leg", Proc. of IEEE ICRA, Roma, Italy, 2007.

[11] F.Schillebeeckx, J. Peirs, W.Van de Vijver, D. Reynaerts, "Compact Zero-Backlash Tilt-Pan Mechanism Based on Differential Gear Technology", Actuator 2004, $9^{\text {th }}$ International Conference on New Actuators, Bremen, Germany, 14-16 June 2004.

[12] V. M. Zatsiorsky, "Kinematics of Human Motion". ISBN: 08801 16765,1998

[13] B. Bresler, J. P. Frankel, "The forces and moments in the leg during level walking". Trans. Am. Soc. Mech. Eng. 72, 27 -36. 1950.

[14] A. Winter, "Biomechanics and motor control of human movement", $2^{\text {nd }}$ ed., ISBN 0-471-50908-6, USA, 1980.

[15] M. Kuster, S. Sakurai, G.A. Wood, "Kinematic and kinetic comparison of downhill and level walking”. Clinical Biomechanics. 1995, Issue 10, pp.79-84

[16] A. McIntosh, K. Beatty, L. Dwan, D. Vickers, "Gait dynamics on an inclined walkway". J Biomechanics, vol. 39, pp. 491-502, 2006.

[17] C.E. Clauser, J.T. McConville, J.W. Young J.W (1969), “Weight, volume and center of mass of segments of the human body" AMRL TR 69-70, Wright-Patterson Air Force Base, Ohio NTIS no. AD-710 622).

[18] P. de Leva, "Adjustment to Zatsiorsky- Seluyanov's segment inertia parameters" J. Biomechanics Vol. 29, No.9, pp. 1223-1230, 1996.

[19] P. de Leva, "Joint center longitudinal position computed from a selected subset of Chandler's data". J. Biomechanics 29, 1996.

[20] V. M. Zatsiorsky, L.M. Raitsin, V.N. Seluyanov, A.S. Aruin, B.J. Prilutzky, "Biomechanical Characteristics of the human body. In Biomechanics and Performance in Sport" Edited by Baumann, W.), pp. 71-83 Bundeninstitut fur Sportwissenschaft, Germany 1993.

[21] R. B. Stein, P. Zehr, M. K. Lebiedowska, D. B. Popovic, "Estimating Mechanical Parameters of Leg Segments in Individuals with and without Physical Disabilities", IEEE Trans. on Rehabilitation Engineering, Vol. 4, No. 3, September 1996.

[22] Barrett WAM Arm Barrett Technology ${ }^{\circledR}$ Inc. (C1998-2004, [Online] Available: http://www.barrett.com/robot/index.htm

[23] P. Garrec, J. P. Martins, J. P. Friconneau, "A new Technology for Portable Exoskeletons" AMSE 2004-Vol 65 n 7/8, pp 13-22.

[24] P. Garrec, J.P. Friconneau, F. Loveau, "Virtuose 6D: a new force-control master arm using innovative ball-screw actuators", Proceedings of OSR $2004-35^{\text {th }}$ Symposium on Robotics, Paris, France march 2004. 